\title{
Collateral transgression of planetary boundaries due to climate engineering by terrestrial carbon dioxide removal
}

\author{
Vera Heck ${ }^{1,3}$, Jonathan F. Donges ${ }^{1,2}$, and Wolfgang Lucht ${ }^{1,3,4}$ \\ ${ }^{1}$ Earth System Analysis, Potsdam Institute for Climate Impact Research, Telegraphenberg A62, \\ 14473 Potsdam, Germany \\ ${ }^{2}$ Stockholm Resilience Centre, Stockholm University, Kräftriket 2B, 11419 Stockholm, Sweden \\ ${ }^{3}$ Department of Geography, Humboldt University, Unter den Linden 6, 10099 Berlin, Germany \\ ${ }^{4}$ Integrative Research Institute on Transformations of Human-Environment Systems, Humboldt University, \\ Unter den Linden 6, 10099 Berlin, Germany
}

Correspondence to: Vera Heck (heck@ pik-potsdam.de)

\author{
Received: 4 May 2016 - Published in Earth Syst. Dynam. Discuss.: 17 May 2016 \\ Revised: 26 September 2016 - Accepted: 27 September 2016 - Published: 31 October 2016
}

\begin{abstract}
The planetary boundaries framework provides guidelines for defining thresholds in environmental variables. Their transgression is likely to result in a shift in Earth system functioning away from the relatively stable Holocene state. As the climate system is approaching critical thresholds of atmospheric carbon, several climate engineering methods are discussed, aiming at a reduction of atmospheric carbon concentrations to control the Earth's energy balance. Terrestrial carbon dioxide removal (tCDR) via afforestation or bioenergy production with carbon capture and storage are part of most climate change mitigation scenarios that limit global warming to less than $2{ }^{\circ} \mathrm{C}$.

We analyse the co-evolutionary interaction of societal interventions via tCDR and the natural dynamics of the Earth's carbon cycle. Applying a conceptual modelling framework, we analyse how the degree of anticipation of the climate problem and the intensity of tCDR efforts with the aim of staying within a "safe" level of global warming might influence the state of the Earth system with respect to other carbon-related planetary boundaries.

Within the scope of our approach, we show that societal management of atmospheric carbon via tCDR can lead to a collateral transgression of the planetary boundary of land system change. Our analysis indicates that the opportunities to remain in a desirable region within carbon-related planetary boundaries only exist for a small range of anticipation levels and depend critically on the underlying emission pathway. While tCDR has the potential to ensure the Earth system's persistence within a carbon-safe operating space under low-emission pathways, it is unlikely to succeed in a business-as-usual scenario.
\end{abstract}

\section{Introduction}

Rockström et al. (2009) introduced the concept of a safe operating space (SOS) for humanity, delineated by nine global planetary boundaries, some of which take into account the existence of tipping points or nonlinear thresholds in the Earth system (Lenton et al., 2008; Schellnhuber, 2009; Kriegler et al., 2009) and may frame sustainable development. Particularly, the state of the Earth system with respect to climate change has received strong political atten- tion as atmospheric carbon concentrations have already entered the uncertainty zone of the planetary boundary of climate change, set at an atmospheric $\mathrm{CO}_{2}$ concentration of 350 to 450 ppmv (Steffen et al., 2015).

The Paris climate agreement (UNFCCC, 2015) aims at limiting global temperature increase to well below $2{ }^{\circ} \mathrm{C}$ above pre-industrial levels, while greenhouse gas emissions are still currently growing. Fuss et al. (2014) have highlighted that more than $85 \%$ of IPCC scenarios that are consistent with the $2{ }^{\circ} \mathrm{C}$ goal require net negative emis- 
sions before 2100. Particularly, terrestrial carbon dioxide removal (tCDR) via afforestation or large-scale cultivation of biomass plantations for the purpose of bioenergy production has been included in recent IPCC scenarios (van Vuuren et al., 2011; Kirtman et al., 2013). Furthermore, tCDR has been proposed as a climate engineering (CE) method that could be applied in case global efforts in mitigating anthropogenic greenhouse gas emissions fail to prevent dangerous climate change (Caldeira and Keith, 2010).

In the context of the SOS framework, tCDR via largescale biomass plantations could extract carbon from the atmosphere via the natural process of photosynthesis (Shepherd et al., 2009). If the carbon accumulated in biomass is harvested and stored in deep reservoirs or used for bioenergy production in combination with carbon capture and storage (Caldeira et al., 2013), further transgression of the climate change boundary and initial transgression of the ocean acidification boundary could be prevented. On the other hand, tCDR is likely to have unintended impacts on other Earth system components besides atmospheric carbon concentrations that is mediated by the global cycles of carbon, water and other biogeochemical compounds (Vaughan and Lenton, 2011). For example, large-scale biomass plantations would require substantial amounts of fertiliser, irrigation water and land area, driving the Earth system closer to the planetary boundaries for biogeochemical flows, freshwater use and land system change, respectively (Heck et al., 2016). The tCDR in the form of afforestation would not be accompanied by most of these negative trade-offs. However, afforestation only has a limited potential to increase the terrestrial carbon storage while all emitted fossil carbon remains a part of the active carbon cycle. Thus, the potentials of tCDR via afforestation are small and afforestation is not included as a tCDR method in this study.

Social and political actions are important drivers of tCDR. The willingness to engage in $\mathrm{CE}$ or mitigation is based on monitoring of the climate system and can be expected to increase as the climate system approaches the normatively assigned climate change boundary. A holistic assessment and systemic understanding of CE therefore requires an analysis of the social and ecological co-evolutionary system.

A dynamic integration of complex interactions between the social and ecological components of the Earth system to simulate in detail the co-evolution of societies and the environment is currently unfeasible due to fundamental conceptual problems and high computational demands on both modelling sides (van Vuuren et al., 2012, 2016). An emerging field of low-complexity models explores new pathways for understanding social-ecological Earth system dynamics (e.g. Brander and Taylor, 1998; Kellie-Smith and Cox, 2011; Jarvis et al., 2012; Anderies et al., 2013; Motesharrei et al., 2014). For example, first simulation approaches have been reported using such conceptual models to simulate the interaction between human climate monitoring and societal action in the form of transitions to renewable energy (Jarvis et al.,
2012) or climate engineering (MacMartin et al., 2013). While not aiming for realism in their quantitative evaluations, the low complexity of such conceptual models allows to understand the structure and effects of dominating feedbacks and their leading interactions, which are otherwise often hidden in the complexity of state-of-the-art full-complexity Earth system models.

In this paper, we provide a conceptual but systematic analysis of the nonlinear system response to using tCDR for steering the Earth system within the SOS defined by planetary boundaries as quantified by Rockström et al. (2009) and Steffen et al. (2015). Specifically, we analyse how the tradeoffs between tCDR and other planetary boundaries depend on the achievable rate and threshold of tCDR implementation; and whether particular combinations of climate and management parameterisations can safeguard a persistence within the SOS. As a starting point, we focus on a subset of the nine proposed planetary boundaries that are most important in the context of tCDR. These are the carbon-related boundaries on climate change, ocean acidification and land system change.

We utilise a conceptual model of the carbon cycle and expand it to explore feedbacks within and between societal and ecological spheres, while being sufficiently simple to permit an analysis of its state and parameter spaces in the form of constrained stability analysis similar to van Kan et al. (2016). We do not aim to provide a quantitative assessment because in this exploratory study, we choose to use a computationally efficient conceptual model to shed light onto the qualitative structure of co-evolutionary dynamics. The approach proposed here can be transferred to models of higher complexity to the extent that this is computationally feasible.

This paper is structured as follows: following the introduction (Sect. 1) we present a co-evolutionary model of societal monitoring and tCDR intervention in the Earth's carbon cycle and related parameter calibration procedures (Sect. 2). Subsequently, we present and discuss our results (Sect. 3) and finish with conclusions (Sect. 4).

\section{Methods}

In social-ecological systems modelling, societal influences and ecological responses are recognised as equally important (Berkes et al., 2000). Therefore, it can be considered essential that representations of social and ecological systems are of the same order of complexity. Increasing complexity of only one model component would not increase the accuracy of information generated by the full coupled model, but would greatly increase computational demand. In view of our objective, we require a sufficiently simple model that conceptually captures the most important processes of global carbon dynamics with respect to planetary boundaries, as well as a stylised societal management feedback loop consisting of tCDR interventions and monitoring of the climate system. 


\subsection{Co-evolutionary model of societal monitoring and tCDR intervention in the carbon cycle}

The basis of our co-evolutionary model is the conceptual carbon cycle model by Anderies et al. (2013). The model covers the most basic interactions between terrestrial, atmospheric and marine carbon pools, and was developed specifically to enable a bifurcation analysis of carbon-related planetary boundaries and their interactions. We modified atmosphereland interactions for a better representation of empirically observed Earth system carbon dynamics and extended the model by a stylised societal management feedback loop mimicking the current focus of international policy processes on climate change. We calibrated the model in order to represent global carbon cycle dynamics consistent with observational data and simulations from detailed high-resolution Earth system models (Sect. 2.2). In the following, we provide an overview of the fundamental model equations. A detailed motivation of the model design and underlying assumptions are given in Anderies et al. (2013).

The adapted model consists of five interacting carbon pools: land $C_{\mathrm{t}}(t)$, atmosphere $C_{\mathrm{a}}(t)$, upper-ocean $C_{\mathrm{m}}(t)$, geological fossil reservoirs $C_{\mathrm{f}}(t)$ and a potential CE carbon sink $C_{\mathrm{CE}}(t)$ (Fig. 1). All model equations are summarised in Table 1 . Note that only the upper-ocean carbon pool is included because the movement of carbon into the deep ocean occurs on longer timescales relative to those of interest, as discussed by Anderies et al. (2013). The land carbon pool combines soil and vegetation carbon pools, implying a simple proportional partitioning of aboveground and belowground carbon pools (Anderies et al., 2013). These simplifications have been adopted because they reduce the number of state variables and we were able to qualitatively reproduce the dynamics of observed carbon pool evolution with the adapted model.

The co-evolutionary dynamics of the system is determined by Eqs. (1)-(5). Conservation of mass (Eq. 1) dictates that the active carbon in the system, i.e. the sum of terrestrial, atmospheric and maritime carbon is equal to the active carbon at pre-industrial times $\left(C_{0}\right)$ plus carbon released from fossil reservoirs $\left(C_{\mathrm{r}}(t)\right)$ minus carbon extracted via tCDR $\left(C_{\mathrm{CE}}(t)\right)$ to permanent stores. Fossil carbon release (Eq. 2 ) is approximated by a logistic function parameterised by the maximum emitted carbon $c_{\max }$ and rate of carbon release $r_{i}$.

The social management feedback loop is motivated by proposals of $\mathrm{CE}$ as a management intervention in response to intolerable levels of global warming. It comprises atmospheric carbon monitoring and tCDR action conditional on the proximity to a critical threshold of atmospheric carbon content (Eq. 3). CE action is implemented via a tCDR carbon offtake from terrestrial carbon $\left(H_{\mathrm{CE}}(t)\right)$ and storage in a permanent (geological) sink $C_{\mathrm{CE}}$. Carbon offtake for tCDR (Eq. 11) is defined analogous to human offtake for agriculture or land-use change (Eq. 13), however, with a dynamic offtake rate $\alpha_{\mathrm{CE}}\left(C_{\mathrm{a}}(t)\right)$ (Eq. 12).

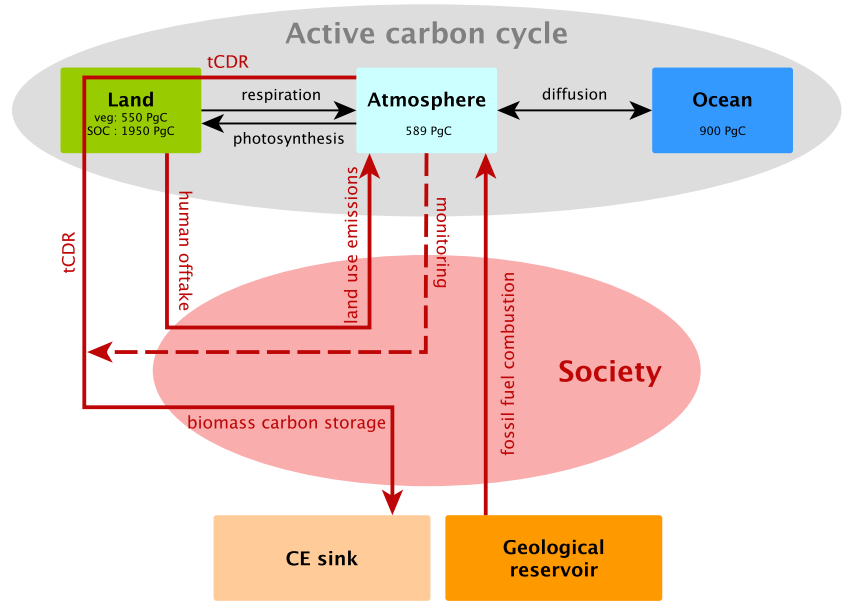

Figure 1. Structure of the co-evolutionary model of societal monitoring and terrestrial carbon dioxide removal (tCDR) intervention in the carbon cycle including simulated components of the carbon cycle as well as a societal management feedback loop and their interactions. Carbon fluxes are indicated as solid lines and coloured red if influenced by society. Carbon values in the boxes indicate estimates of pre-industrial carbon pools in the year 1750 AD (Batjes, 1996; Ciais et al., 2013). CE sink is the climate engineering sink.

The tCDR characteristics are governed by three parameters: (i) implementation threshold $\left(\widetilde{C_{\mathrm{a}}}\right)$ in terms of atmospheric carbon content, representing societal foresightedness, (ii) maximally achievable rate of $\operatorname{tCDR}\left(\alpha_{\max }\right)$, a measure of societies' efforts, as well as biogeochemical constraints and (iii) the slope of tCDR implementation $\left(s_{\mathrm{CE}}\right)$, parameterising social and economic implementation capacities. Figure 2 depicts an exemplary tCDR trajectory for constant terrestrial carbon in Eq. (11) for two values of $s_{\mathrm{CE}}$. The implementation time can be computed from the slope of tCDR implementation by using current increase rates of atmospheric carbon as a conversion factor. With current increase rates of approximately $2 \mathrm{ppmv} \mathrm{a}^{-1}$ (Tans and Keeling, 2015), the two depicted values of $s_{\mathrm{CE}}$ correspond to tCDR ramp-up times of approximately 20 and 40 years (from 10 to $90 \%$ capacity) for $s_{\mathrm{CE}}=0.1 \mathrm{ppmv}^{-1}$ (solid) and $s_{\mathrm{CE}}=$ $0.05 \mathrm{ppmv}^{-1}$ (dashed), respectively.

The atmosphere-ocean carbon feedback (Eq. 4) is governed by diffusion, which in the model is assumed to depend on the difference between atmospheric and maritime carbon pools.

Land-atmosphere interaction is determined by both ecological and social processes: the net ecosystem productivity (Eq. 6), tCDR offtake (Eq. 11) and other human offtake for agriculture and other land use (Eq. 13), respectively.

Net ecosystem productivity is given by the net carbon flux of photosynthesis (Eq. 8) and respiration (Eq. 9), multiplied by the terrestrial carbon pool and a logistic dampening function which represents competition for space, sunlight, water or nutrients. Both photosynthesis and respiration are con- 
Table 1. Summary of equations describing the co-evolutionary model of societal monitoring and tCDR intervention in the carbon cycle building upon Anderies et al. (2013). The unit a is years.

\begin{tabular}{lll}
\hline Process & Equation & \\
\hline Conservation of mass & $C_{\mathrm{t}}(t)+C_{\mathrm{a}}(t)+C_{\mathrm{m}}(t)=C_{0}+C_{\mathrm{r}}(t)-C_{\mathrm{CE}}(t)$ & $(1)$ \\
Fossil carbon release & $\dot{C}_{\mathrm{r}}(t)=r_{i} C_{\mathrm{r}}(t)\left(1-\frac{C_{\mathrm{r}}(t)}{C_{\mathrm{max}}}\right)$ & $(2)$ \\
CE carbon storage & $\dot{C}_{\mathrm{CE}}(t)=H_{\mathrm{CE}}\left(C_{\mathrm{t}}(t), C_{\mathrm{a}}(t)\right)$ & $(3)$ \\
Atmosphere-ocean diffusion & $\dot{C}_{\mathrm{m}}(t)=a_{\mathrm{m}}\left(C_{\mathrm{a}}(t)-\beta C_{\mathrm{m}}(t)\right)$ & $(4)$ \\
Terrestrial carbon flux & $\dot{C}_{\mathrm{t}}(t)=\mathrm{NEP}\left(C_{\mathrm{a}}(t), C_{\mathrm{t}}(t)\right)-H\left(C_{\mathrm{t}}(t)\right)-H_{\mathrm{CE}}\left(C_{\mathrm{t}}(t), C_{\mathrm{a}}(t)\right)$ & $(5)$ \\
\hline Net ecosystem productivity & $\mathrm{NEP}\left(C_{\mathrm{a}}(t), C_{\mathrm{t}}(t), T(t)\right)=r_{\mathrm{tc}}[P(T(t))-R(T(t))] C_{\mathrm{t}}(t)\left[1-\frac{C_{\mathrm{t}}(t)}{K\left(C_{\mathrm{a}}(t)\right)}\right]$ & $(6)$ \\
Terrestrial carbon carrying capacity & $K\left(C_{\mathrm{a}}(t)\right)=a_{k} e^{-b_{k} C_{\mathrm{a}}(t)+c_{k}}$ & $(7)$ \\
Photosynthesis & $P(T(t))=a_{\mathrm{p}} T(t)^{b_{\mathrm{p}}} e^{-c_{\mathrm{p}} T(t)}$ & $(8)$ \\
Respiration & $R(T(t))=a_{\mathrm{r}} T(t)^{b_{\mathrm{r}}} e^{-c_{\mathrm{r}} T(t)}$ & $(9)$ \\
Temperature & $T\left(C_{\mathrm{a}}(t)\right)=a_{T} C_{\mathrm{a}}(t)+b_{T}$ & $(10)$ \\
\hline tCDR offtake flux & $H_{\mathrm{CE}}\left(C_{\mathrm{t}}(t), C_{\mathrm{a}}(t)\right)=\alpha_{\mathrm{CE}}\left(C_{\mathrm{a}}(t)\right) C_{\mathrm{t}}(t)$ & $(11)$ \\
Societal tCDR offtake rate & $\alpha_{\mathrm{CE}}\left(C_{\mathrm{a}}(t)\right)=\alpha_{\max }\left(1+\exp \left(-s_{\mathrm{CE}}\left(C_{\mathrm{a}}(t)-\widetilde{C}_{\mathrm{a}}\right)\right)\right.$ & $(12)$ \\
Other human biomass offtake flux & $H\left(C_{\mathrm{t}}(t)\right)=\alpha C_{\mathrm{t}}(t)$ & $(13)$ \\
\hline
\end{tabular}

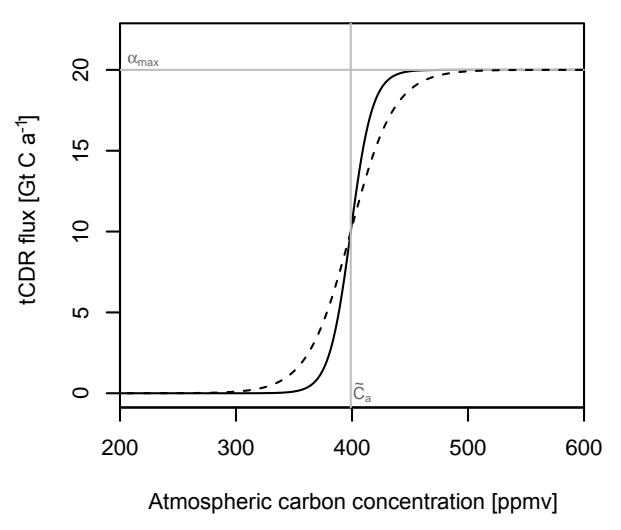

Figure 2. Sigmoidal dependence of the tCDR flux on atmospheric carbon concentrations for two values of the tCDR implementation capacity parameter (slope): $s_{\mathrm{CE}}=0.1 \mathrm{ppmv}^{-1}$ (solid line) and $s_{\mathrm{CE}}=0.05 \mathrm{ppmv}^{-1}$ (dashed line). The threshold parameter $\left(\widetilde{C_{\mathrm{a}}}\right)$ is set at $400 \mathrm{ppmv}$ atmospheric carbon concentration and the potentially achievable tCDR flux is parameterised with $\alpha_{\max }=$ $20 \mathrm{GtCa}^{-1}$.

tinuous functions of global land temperature $(T(t)$, Eq. 10), which in turn depends linearly on atmospheric carbon content. It is important to note that in our model, respiration exceeds photosynthesis for higher temperatures (Fig. 3). The state of equilibrium of the terrestrial carbon pool is thus determined by the land surface temperature, as well as the terrestrial carbon carrying capacity (Eq. 7) in the density function. In contrast to Anderies et al. (2013), we implement a dynamic terrestrial carbon carrying capacity as a function of atmospheric carbon content. This is motivated by a number of factors such as $\mathrm{CO}_{2}$ fertilisation and a higher water-use efficiency under higher atmospheric carbon concentrations, as well as higher average vegetation density in a warmer world

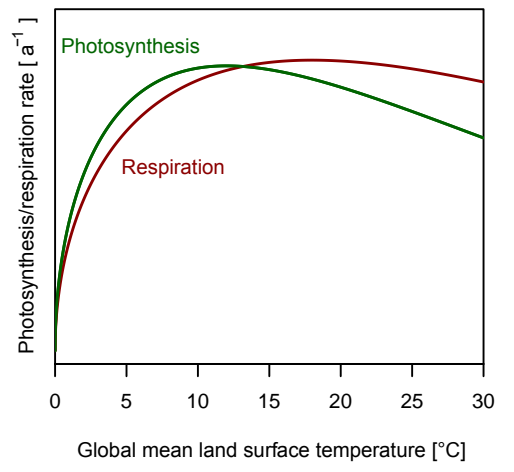

Figure 3. Modelled photosynthesis and respiration rates as a function of global mean land surface temperature.

(e.g. Drake et al., 1997; Keenan et al., 2013). For low atmospheric carbon we assume a rapid increase in terrestrial carbon storage capacity as a function of atmospheric carbon concentration and a saturation of storage capacity for high atmospheric carbon, in line with assessments of coupled carbon cycle climate models (Heimann and Reichstein, 2008). The functional relationship in Eq. (7) follows these constraints for chosen parameter values (Sect. 2.2).

\subsection{Calibration of model parameters}

A sufficiently suitable application of a conceptual model in the context of the planetary boundaries as in Steffen et al. (2015) requires the model's ability to simulate credible transients of global carbon dynamics. In order to achieve this, we calibrated model parameters to observed carbon fluxes and pools, as well as simulation results of detailed highresolution Earth system models. 
Because we simulate relative dynamics between the different carbon compartments and do not aim at prognostics of actual time evolution of carbon pools, all carbon fluxes and pools are normalised to the active carbon at pre-industrial times, i.e. the total sum of pre-industrial carbon in the year 1750 AD (3989 Gt C, Fig. 1). All normalised parameter values are summarised in Table 2.

\subsubsection{Temperature}

For the calibration of the linear relationship between temperature and atmospheric carbon content (Eq. 10) we used the transient climate response to cumulative emissions (TCRE) with a reported global mean surface temperature increase per emitted carbon of $2 \mathrm{~K} / 1000 \mathrm{GtC}$ (Joos et al., 2013; Gillett et al., 2013). Assuming an airborne fraction of 0.5 (Knorr, 2009; Gloor et al., 2010), the global mean temperature increase rate per atmospheric carbon increase (Eq. 10) is approximately twice the temperature increase rate of emitted carbon (TCRE), i.e. $2 \mathrm{~K} / 500 \mathrm{GtC}$ in the atmosphere. From this global surface temperature increase rate (twothirds ocean and one-third land surface), the global land surface temperature increase can be inferred via the global land / sea warming ratio of approximately 1.6 (Sutton et al., 2007). Thus, we approximate a global land surface warming rate of $5.3 \mathrm{~K} / 1000 \mathrm{GtC}$ that remains in the atmosphere. The $y$-offset $\left(b_{T}\right.$ in Eq. 10) was inferred via global land surface temperature anomalies from 1880-2000 (Jones et al., 2012), a global average (1880-2000) land temperature of $8.5^{\circ} \mathrm{C}$ (NOAA, 2015) and observed monthly mean $\mathrm{CO}_{2}$ concentrations (Mauna Loa, 1959-2000, Tans and Keeling, 2015).

\subsubsection{Ocean-atmosphere dynamics}

The carbon solubility in sea water factor $(\beta)$ is directly determined by the assumption of pre-industrial equilibrium between upper-ocean carbon and atmospheric carbon $\left(C_{\mathrm{m}} \cdot(0)=\right.$ $0)$. From this and a present carbon flux from the atmosphere to the ocean of $\dot{C}_{\mathrm{m}}\left(t_{\mathrm{tod}}\right)=2.3 \mathrm{GtC} \mathrm{a}^{-1}$ (Ciais et al., 2013), follows the atmosphere-ocean diffusion coefficient $a_{m}$.

\subsubsection{Terrestrial dynamics}

Photosynthesis and respiration are calibrated according to temperature relationships reported in the literature. However, literature generally specifies temperature relationships at small temporal- and spatial-scales in controlled environments, whereas our model equations refer to a global average of day and night-time temperature. Thus, only a rough estimation of the relationship between temperature and photosynthesis / respiration for model calibration is possible. As in Anderies et al. (2013), we assume maximum respiration at a global land surface temperature of $18^{\circ} \mathrm{C}$ (supported by Yuan et al. (2011)), determining the ratio of parameters $b_{\mathrm{r}} / c_{\mathrm{r}}=18^{\circ} \mathrm{C}$ (Fig. 3). We choose a maximum of photosyn-

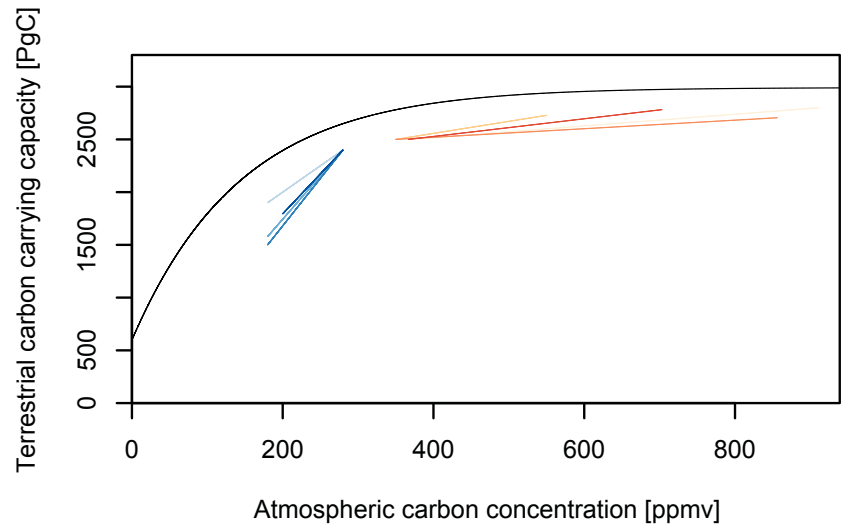

Figure 4. Approximated terrestrial carbon carrying capacity (black line). Blue lines represent approximate changes in terrestrial carbon storage published in Crowley (1995), François et al. (1998), Kaplan et al. (2002) and Joos et al. (2004). Red lines represent simulated changes in terrestrial carbon storage due to climate change reported by Joos et al. (2001), Lucht et al. (2006) and Friend et al. (2013).

thesis at $12{ }^{\circ} \mathrm{C}$, incorporating a $\mathrm{CO}_{2}$ fertilisation feedback indirectly via the dependence of temperature on atmospheric carbon $\left(b_{\mathrm{p}} / c_{\mathrm{p}}=12^{\circ} \mathrm{C}\right)$. The amplitudes of photosynthesis and respiration functions ( $a_{\mathrm{r}}$ and $a_{\mathrm{p}}$, respectively) are approximated for agreement with carbon fluxes reported in Ciais et al. (2013). Note that the functional form of carbon fluxes is not decisive for the model dynamics, however, it is important that the curves of photosynthesis and respiration intersect at some temperature limit where ecosystem respiration exceeds photosynthesis. With our parameterisation this is the case at a global mean land surface temperature of approximately $13^{\circ} \mathrm{C}$, which is $4.5^{\circ} \mathrm{C}$ warmer than the 20th century average global mean land surface temperature (NOAA, 2015). This is in line with multi-model assessments in carbon reversal studies (e.g. Heimann and Reichstein, 2008; Friend et al., 2013).

The terrestrial carbon carrying capacity $K\left(C_{\mathrm{a}}(t)\right)$ in $\dot{C}_{t}(t)$ determines how much carbon can be accumulated in the terrestrial system at maximum, as long as photosynthesis exceeds respiration (refer to Eq. 6). $K\left(C_{\mathrm{a}}(t)\right)$ was calibrated to represent both past long-term climatic and terrestrial carbon changes (last glacial maximum to Holocene) (Crowley, 1995; François et al., 1998; Kaplan et al., 2002; Joos et al., 2004), and prognostics of climate change impacts on terrestrial carbon storage (Joos et al., 2001; Lucht et al., 2006; Friend et al., 2013) to capture terrestrial changes due to climate variability (Fig. 4).

Human activities such as fires, deforestation and agricultural land use that affect terrestrial carbon stocks are summarised as human offtake of biomass and are presently estimated at $H\left(t_{\text {tod }}\right)=1.1 \mathrm{GtC} \mathrm{a}^{-1}$ (Ciais et al., 2013). With a present terrestrial carbon pool of $C_{\mathrm{t}}\left(t_{\mathrm{tod}}\right)=2470 \mathrm{GtC}$ we calculate the human offtake rate $\alpha=H\left(t_{\text {tod }}\right) / C_{\mathrm{t}}\left(t_{\mathrm{tod}}\right)$. 
Table 2. Calibrated model parameters after normalisation to pre-industrial carbon pools. Remaining units are years (a) and temperature (20 K).

\begin{tabular}{llll}
\hline Parameter & Symbol & Value & Unit \\
\hline Ecosystem-dependent conversion factor & $r_{\mathrm{tc}}$ & 2.5 & $\mathrm{a}^{-1}$ \\
Scaling factor for photosynthesis $P(T)$ & $a_{\mathrm{p}}$ & 0.48 & $(20 \mathrm{~K})^{-b_{\mathrm{p}}}$ \\
Scaling factor for respiration $R(T)$ & $a_{\mathrm{r}}$ & 0.40 & $(20 \mathrm{~K})^{-b_{\mathrm{r}}}$ \\
Power law exponent for increase in $P(T)$ for low $T$ & $b_{\mathrm{p}}$ & 0.5 & 1 \\
Power law exponent for increase in $R(T)$ for low $T$ & $b_{\mathrm{r}}$ & 0.5 & 1 \\
Rate of exponential decrease in $P(T)$ for high $T$ & $c_{\mathrm{p}}$ & 0.556 & $(20 \mathrm{~K})^{-1}$ \\
Rate of exponential decrease in $R(T)$ for high $T$ & $c_{\mathrm{r}}$ & 0.833 & $(20 \mathrm{~K})^{-1}$ \\
Scaling factor for terrestrial carbon carrying capacity & $a_{k}$ & -0.6 & 1 \\
Rate of exponential increase in terrestrial carbon carrying capacity & $b_{k}$ & 13.0 & 1 \\
Offset for terrestrial carbon carrying capacity & $c_{k}$ & 0.75 & 1 \\
Human terrestrial carbon offtake rate & $\alpha$ & 0.0004 & $\mathrm{a}^{-1}$ \\
\hline Slope of $T-C_{\mathrm{a}}$ relationship & $a_{T}$ & 1.06 & $20 \mathrm{~K}$ \\
Intercept of $T-C_{\mathrm{a}}$ relationship & $b_{T}$ & 0.227 & $20 \mathrm{~K}$ \\
\hline Carbon solubility in sea water factor & $\beta$ & 0.654 & 1 \\
Atmosphere-ocean diffusion coefficient & $a_{m}$ & 0.0166 & $20 \mathrm{~K}$ \\
\hline * Atmospheric carbon threshold of tCDR implementation & $\widetilde{C_{\mathrm{a}}}$ & $0-0.3$ & 1 \\
Rapidity of tCDR ramp-up (tCDR implementation capacity) & $s_{\mathrm{CE}}$ & 200 & 1 \\
$*$ Maximum tCDR rate & $\alpha_{\mathrm{max}}$ & $0-0.03$ & $\mathrm{a}^{-1}$ \\
\hline * Size of geological fossil carbon stock & $c_{\mathrm{max}}$ & $0-0.51$ & 1 \\
Industrialisation rate & $r_{i}$ & 0.03 & $\mathrm{a}^{-1}$ \\
\hline Climate change boundary & $b_{\mathrm{a}}$ & 0.21 & 1 \\
Land system change boundary & $b_{1}$ & 0.59 & 1 \\
Ocean acidification boundary & $b_{\mathrm{m}}$ & 0.31 & 1 \\
\hline Pang & & & \\
\hline
\end{tabular}

* Parameters are varied during the analysis and the parameter range is stated.

\subsubsection{Fossil fuel emissions}

The size of the geological fossil carbon stock $c_{\max }$ determines the carbon released from fossil reservoirs (Eq. 2) and plays an important role for carbon dynamics (Sect. 3.4). In the scope of this study, $c_{\max }$ is varied to assess different baseline emissions following the cumulative emissions of the representative concentration pathways (RCPs). RCP2.6 is a low-emission scenario with cumulative emissions of approximately $880 \mathrm{GtC}\left(c_{\max }=0.2\right)$ (van Vuuren et al., 2011). The two medium emission scenarios RCP4.5 and RCP6.0 have cumulative emissions of approximately $1200 \mathrm{GtC}\left(c_{\max }=\right.$ $0.31)$ (Thomson et al., 2011) and $1400 \mathrm{GtC}\left(c_{\max }=0.36\right)$ (Masui et al., 2011), respectively. RCP8.5 represents a business as usual scenario with cumulative emissions of approximately $2000 \mathrm{GtC}\left(c_{\max }=0.51\right)$ (Riahi et al., 2011).

\subsection{Planetary boundaries}

We use the carbon-related planetary boundaries (climate change, ocean acidification and land system change) to define the desirability of given trajectories of carbon pool evo- lution. The proposed locations of these boundaries are normalised to match the normalisation of our model.

The planetary boundary for climate change is proposed at 350 ppmv $\mathrm{CO}_{2}$ equivalents in the atmosphere with an uncertainty range to $450 \mathrm{ppmv}$ (Steffen et al., 2015). For our study we take the middle of the uncertainty range ( $400 \mathrm{ppmv}$ ) because critical atmospheric thresholds are likely to be located somewhere within the uncertainty range and obtain a normalised climate change boundary is at 0.21 atmospheric carbon. Ocean acidification is measured via the saturation state of aragonite and its boundary is set at $80 \%$ of the preindustrial average annual global saturation state of aragonite (Steffen et al., 2015). Since chemical processes are not explicitly represented in our model, this measure is not directly transferable to maritime carbon content. This measure is not directly transferable to maritime carbon content because it largely depends on chemical variables such as $\mathrm{pH}-$ value, ocean alkalinity and dissolved inorganic carbon that are not included in the model. At the current carbon content $(1150 \mathrm{GtC})$, the saturation state of aragonite is at $84 \%$ of the pre-industrial value (Guinotte and Fabry, 2008). We therefore estimate the normalised ocean acidification boundary at 0.31 , about $5 \%$ higher than the current value of the marine 
carbon stock (0.29). The land system change boundary is defined in terms of the amount of remaining forest cover, motivated by critical biogeophysical feedbacks of forest biomes to the physical climate system (Steffen et al., 2015). The global boundary has been specified as $75 \%$ of global forest cover remaining (Steffen et al., 2015). Due to the lack of biogeophysical feedbacks in the model, we translate deforestation into carbon content by measuring the loss of vegetation carbon with deforestation. We thereby neglect vegetation carbon of all non-forest biomes, while at the same time neglecting soil carbon changes by deforestation (Heck et al., 2016), thus approximating that soil carbon changes by deforestation are of the same order of magnitude as vegetation carbon pools of non-forest biomes. With vegetation carbon of $550 \mathrm{GtC}$ (Ciais et al., 2013), we obtain a normalised land system change boundary at 0.59 .

Note that the exact location and normalisation of the boundaries is not decisive for our results because we qualitatively analyse the influence of tCDR management on the existence of desirable trajectories. Slightly different sets of planetary boundaries would not qualitatively change the systemic effects reported in this study.

\subsection{Model analysis and terminology}

Our analysis of the co-evolutionary system aims at assessing transient dynamics of carbon pools with respect to planetary boundaries. First, we run the model and exemplarily show the influence of socially controlled parameters of tCDR implementation on the transient carbon pool evolution (Sect. 3.1). It is of particular relevance under what circumstances the simulated carbon pool trajectories (atmosphere, ocean and land) do not cross their respective planetary boundaries. We refer to the regions on the safe side of the planetary boundaries as "safe regions". All carbon pool trajectories remaining in the respective safe region at all times are considered "safe trajectories". For example, all atmospheric carbon trajectories that do not cross the planetary boundary for climate change (i.e. trajectories that are in the safe region of atmospheric carbon) are safe atmospheric carbon trajectories. System states with each carbon pool remaining in its respective safe region are referred to as carbon system states within the SOS, i.e. "safe states".

In a nonlinear dynamical system, trajectories can be sensitive to initial conditions. The pre-industrial distribution of carbon pools, as well as carbon dynamics in the Earth system are relatively well-assessed, while still subject to high uncertainty (Ciais et al., 2013). Furthermore, considerable uncertainty remains with respect to our conceptual model structure and the exact values of planetary boundaries. Bearing in mind these inherent uncertainties, we explore how robust the existence of safe trajectories is under a variation of the initial conditions, i.e. the initial carbon pool distribution and different tCDR characteristics (Sect. 3.2).
Such a variation of initial conditions is also a common approach to conceptualising and measuring resilience of social-ecological systems as the ability to return to an attracting state after a perturbation (Holling, 1973; Scheffer et al., 2001). A suitable approach to quantifying the likelihood of a complex system to return to an attracting state under finite perturbations is basin stability analysis (Menck et al., 2013).

In the context of planetary boundaries, not necessarily all trajectories that approach a "safe attractor" (i.e. an attractor within the SOS associated to all three planetary boundaries) would be considered safe because they could temporarily leave the safe region. The concept of constrained basin stability (van Kan et al., 2016) and related methods (Hellmann et al., 2016) provide generalisations of basin stability that allow taking transient phenomena into account. Similarly to the constrained basin stability approach, we classify different domains in the initial-condition state space based on transient dynamics of carbon pools. The set of initial conditions resulting in safe carbon trajectories form the "safe domain". We refer to this domain as the manageable core of the safe operating space (MCSOS), as it depends on the tCDR management characteristics and the emission pathway. The "undesirable domain" is formed by all initial conditions resulting in a transgression of all three carbon boundaries at some point in time. Remaining state space domains are formed by initial conditions leading to a transgression of a subset of planetary boundaries. They are referred to as the respective partially manageable domains (MDs) (e.g. the land manageable domain is the state space domain of initial conditions with trajectories without a transgression of the land boundary).

The computational efficiency of our model allows for a systematic analysis of the MCSOS and other domains under variation of societal parameters (tCDR management and fossil fuel emissions). We analyse how the size of all domains (MCSOS, partially MDs and the undesirable domain) varies with different tCDR characteristics (Sect. 3.3) and emission pathways (Sect. 3.4). In the spirit of van Kan et al. (2016), the size of (partially) manageable domains can be interpreted as a resilience-like measure of the opportunities to stay within the carbon-related SOS, taking into account inherent structural uncertainties of our model, the location of planetary boundaries, and the pre-industrial carbon pool distribution. Note that the maximum extent of the MCSOS is constrained by the planetary boundaries, but it may differ from the SOS (i.e. the "safe" region) as the safety of the domain is determined by transient system dynamics, whereas the SOS is defined within static planetary boundaries.

\section{Results and Discussion}

\subsection{Carbon system trajectories subject to societal tCDR management loop}

To illustrate how the co-evolutionary social-environmental system evolves with respect to carbon-related planetary 


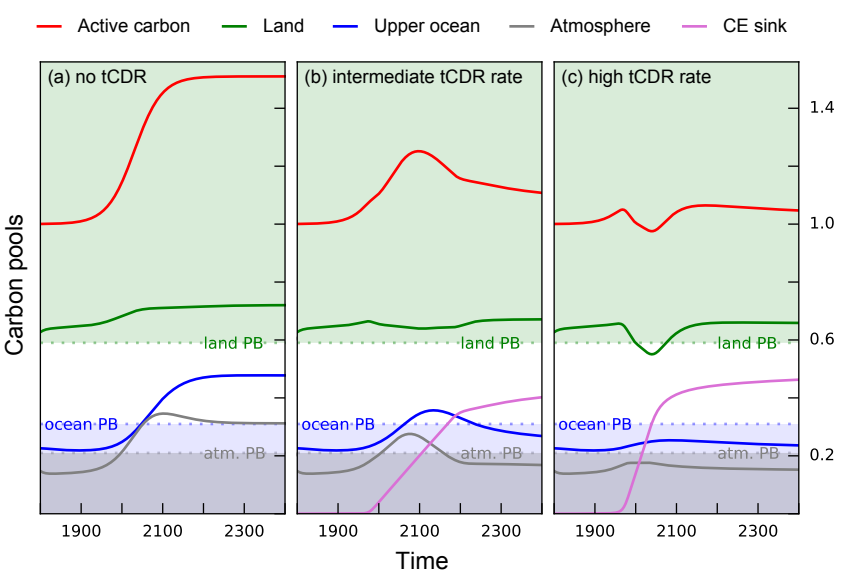

Figure 5. Time evolution of the normalised carbon pools in our model of the carbon system for three tCDR configurations with a high-emission baseline (cumulative emissions as in RCP8.5; Riahi et al., 2011) (a) without tCDR $\left(\alpha_{\max }=0\right)$, (b) intermediate tCDR rate $\left(\alpha_{\max }=0.0025\right)$ and $(\mathbf{c})$ high tCDR rate $\left(\alpha_{\max }=0.025\right)$. Total active carbon (red) is increased by fossil fuel emissions $\left(c_{\max }=\right.$ 0.51 ) with dynamic response of the terrestrial carbon pool (green), maritime carbon pool (blue) and atmospheric carbon pool (grey). The tCDR sink (purple) stores carbon extracted from the active system. Shaded areas represent the respective safe regions of land, ocean and atmosphere in green, blue and grey. Dotted lines indicate the location of the associated planetary boundaries (PBs).

boundaries, Fig. 5 depicts trajectories of the major carbon pools with tCDR adhering to different management characteristics. All trajectories start at their respective normalised pre-industrial state. The normalised planetary boundaries (Sect. 2.3) are indicated as dotted lines and the safe region of each boundary (refer to Sect. 2.4) is shaded in the respective colours. Variation of tCDR characteristics reflects uncertainty about possible tCDR rates related to overall biomass harvesting potentials and societies' implementation capacities (Sect. 2.1).

The emission baseline used for all results displayed in Fig. 5 is a business-as-usual scenario with cumulative emissions as in RCP8.5 (Riahi et al., 2011). Without tCDR (Fig. 5a), all that fossil carbon societies emit into the atmosphere is distributed to ocean, land and atmosphere. This results in more active carbon (red), leading to carbon accumulation in all pools and a transgression of the atmosphere and ocean boundaries. In this emission scenario, the land system accumulates carbon and, thus, moves away from its planetary boundary in our model setting (note that the actual control variable of the planetary boundary of land system change as defined by Steffen et al. (2015) is the remaining forest cover, which would not be directly modified by changing atmospheric carbon concentrations). Moreover, higher emission baselines (results not shown here) can lead to decreasing terrestrial carbon stocks when respiration dominates over photosynthesis due to strong global warming.
In Fig. 5b) and c), the societal tCDR response via harvesting from the terrestrial carbon stock and subsequent storage starts just before the atmospheric boundary is reached $\left(C_{\mathrm{a}}=0.18 \sim 340 \mathrm{ppmv}\right)$. With a low tCDR rate (maximal storage flux of about $\left.7 \mathrm{GtCa}^{-1}, \alpha_{\max }=0.0025\right)$, the $\mathrm{CE}$ sink is filled relatively slowly (Fig. 5b). Thus, a transient transgression of the atmosphere and ocean boundaries cannot be prevented. However, all trajectories re-enter their respective "safe" region after about 150 years. A higher tCDR rate $\left(\alpha_{\max }=0.025\right.$, corresponding to very high-potential storage fluxes of $26 \mathrm{GtCa}^{-1}$ or $5 \%$ of global biomass per year) can prevent a large increase in active carbon and thus prevents the transgression of both atmosphere and ocean boundaries (Fig. 5c). However, extensive harvest from the land carbon pool then leads to a temporary transgression of the land boundary. The implementation of tCDR was thus effective in its purpose of preventing entry into a dangerous region of climate change, but at the cost of exploiting the land system to an extent that crossed the land system change boundary.

These results show that small tCDR rates (Fig. 5b) (or implementation that is too late, results not shown here) do not necessarily keep the system in the SOS. High tCDR rates (Fig. 5c) could seem successful when focusing on the climate change boundary, but might in fact not be feasible if other components of the carbon system are taken into account. In light of ongoing deforestation for the purpose of bioenergy production (Gao et al., 2011), this simulated collateral transgression of the land system change boundary with large-scale tCDR is an important and plausible feature of the model.

In the actual Earth system, a transgression of the land system change boundary might evoke additional trade-offs to the biogeophysical climate system (Foley et al., 2003), which are not represented in the model. For example, large tCDR rates can only be achieved by large-scale land-use change that could alter atmospheric circulations and rainfall patterns (Snyder et al., 2004) even though the carbon-related climate change boundary might not be transgressed with high tCDR rates.

The carbon values stated here are primarily given as an orientation for the reader, and should not be directly interpreted with respect to tCDR feasibility assessments. However, tCDR rates of $7 \mathrm{GtC} \mathrm{a}^{-1}$ are in line with more conservative biomass harvest potentials considering biodiversity conservation and agricultural limits (Dornburg et al., 2010; Beringer et al., 2011). More idealistic assessments of tCDR rates of more than $35 \mathrm{GtC} \mathrm{a}^{-1}$ - assuming high biomass yields of more than one-quarter of global land area - have been reported as well (Smeets et al., 2007). In this context, the range of tCDR rates studied in this paper reflects both conservative and highly optimistic tCDR potentials reported in the literature. 


\subsection{State space domain structure of the Earth's carbon system subject to societal tCDR management loop}

We compute the state space domain structure (refer to Sect. 2.4) from a sample of initial conditions around the preindustrial carbon state. We sample approximately 66000 initial conditions from a regular grid by variation of each carbon pool by \pm 0.2 around the pre-industrial conditions. This range is a pragmatic choice which does not influence the following qualitative analysis. To compute the existing domains, we evolve each initial condition for 600 years in time and colour it according to the domains following from the transient properties of the trajectories of land, atmosphere and ocean carbon, as described above. The mapping of initial conditions sheds light on possible domains in the carbon system and potential transitions into other state space domains in our model of the carbon cycle. In this context, the vicinity of the pre-industrial and current Earth system states to such domain boundaries in the model's initial-carbon-condition state space is of particular relevance.

Figure 6 shows the existing domains without tCDR (a), with intermediate tCDR rates (b) and with very high tCDR rates (c). The emission baseline is the same for all variations of tCDR characteristics, with cumulative emissions of approximately $880 \mathrm{GtC}$, which is comparable to RCP2.6 cumulative emissions (van Vuuren et al., 2011). The current state of the carbon cycle is located in proximity to domain borders, highlighting that it is close to a transgression of the land system and climate change boundaries. Historical emissions and land system changes have moved the state of the carbon cycle closer towards the undesirable domain, and remaining on an emission trajectory similar to RCP2.6 without tCDR results in the non-existence of the MCSOS (Fig. 6a). Thus, the manageable core does not exist if the implementation of tCDR management is not considered by society, even in a relatively low-emission scenario.

Figure $6 \mathrm{~b}$ and $\mathrm{c}$ serve as an example of how human intervention and management by tCDR can influence the size and even the existence of the MCSOS and other domains. With an implementation of tCDR, the MCSOS can be re-established, potentially to its full extent, which is directly determined by the three planetary boundaries (Fig. 6b). Even for a relatively low-emission scenario, the tCDR threshold needs to be at sufficiently low atmospheric carbon content $\left(\widetilde{C_{\mathrm{a}}}=0.16\right)$ to prevent potential boundary transgressions. Nevertheless, because of past land-use change, the current Earth system state is approaching domains with unsafe land system and climate change. If tCDR is applied under the same conditions but with a 10 times higher potential tCDR rate $\left(\alpha_{\max }=0.04\right)$, the MCSOS shrinks due to over-exploitation of the land system for tCDR (Fig. 6c). The land system is overexploited when the total human biomass offtake flux $\left(H_{\mathrm{CE}}+H\right)$ exceeds net ecosystem productivity (NEP). This decreases terrestrial carbon pools (Eq. 5) which in turn limits the potential for tCDR (Eq. 11). In Fig. 6c this occurs under high initial atmospheric carbon concentrations, because these result in a higher tCDR flux for the same potential tCDR rate ( $\alpha_{\max }$, ref. to Fig. 2). The current state of the carbon cycle of the Earth system is out of the MCSOS. In this case, large societal commitment to avoid a transgression of the climate change boundary leads to a collateral transgression of the land system change boundary in our model.

\subsection{Size of manageable domains under variation of tCDR characteristics}

The size and existence of the MCSOS and other state space domains depends on tCDR characteristics (refer to Sect. 2.4). We compute the size of the different initial-condition state space domains depending on the most decisive management parameters, i.e. on the implementation threshold $\widetilde{C_{\mathrm{a}}}$ and on the potential maximum tCDR rate $\alpha_{\max }$. The size of all domains is measured in relation to the size of the considered state space section as depicted in Fig. 6, which is given by a variation of pre-industrial conditions by \pm 0.2 .

Figure 7 depicts the relative size of the MCSOS and the partially manageable domains under baseline emissions of $c_{\max }=0.4$, corresponding to cumulative emissions in the order of RCP6.0. The size of the MCSOS or partially MDs can be interpreted as a form of resilience of the system (i.e. the likelihood that the system stays within the carbon-related SOS). Thus, we measure the resilience of the carbon cycle by the size of MCSOS (i.e. the opportunity of success of tCDR to maintain safe trajectories). This strongly depends on the atmospheric carbon threshold at which tCDR is implemented. Obviously, only the anticipation of an approaching planetary boundary can prevent a transgression thereof. Thresholds higher than the atmospheric carbon boundary $\left(b_{1}=0.21\right)$ are not sufficient in sustaining a MCSOS, because the atmosphere MD disappears by definition at $\widetilde{C_{\mathrm{a}}}=$ 0.21 (grey line in Fig. 7a).

However, strong anticipation coupled with too early tCDR implementation does not necessarily maintain the system within the SOS. If tCDR is initialised at relatively low atmospheric carbon content $\left(\widetilde{C_{\mathrm{a}}}=0.13\right.$ (approximately 330 ppmv) in Fig. 7a), the MCSOS is diminished due to a transgression of the land system change boundary at some point in time. Hence, the window of opportunity for using tCDR as a means of staying in the SOS under this exemplary fossil fuel emission scenario is limited to a relatively narrow range of tCDR implementation thresholds. The size of the land MD shows nonlinear dependence on the tCDR threshold. For thresholds between 0.2 and 0.25 , the land MD is almost diminished (Fig. 7a), because the relatively high tCDR rate $\left(\alpha_{\max }=0.02\right)$ leads to an over-exploitation of the land system (ref. to Sect. 3.2). However, higher tCDR thresholds avoid this over-exploitation and increase the land MD, because of a later onset of tCDR and overall higher NEP due to higher atmospheric carbon content and temperature (Eq. 6). 

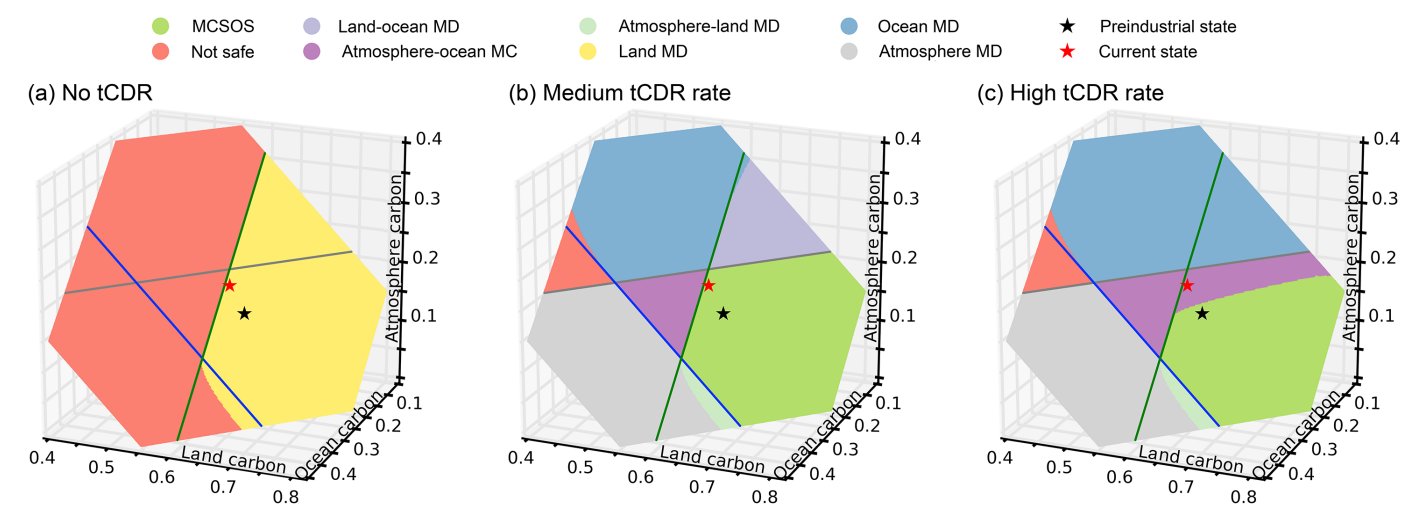

Figure 6. Charting of normalised carbon-system initial-condition state space in our model for three tCDR management characteristics with identical, relatively low-emission baseline $\left(c_{\max }=0.2\right)$ : (a) without tCDR $\left(\alpha_{\max }=0\right)$, (b) intermediate tCDR rates $\left(\alpha_{\max }=0.004\right)$ and (c) high tCDR rates $\left(\alpha_{\max }=0.04\right)$. The two-dimensional plane is formed by sampling initial conditions around the pre-industrial state (variation of carbon stocks by \pm 0.2 while conserving total carbon in the system). Each domain is coloured according to transient properties of trajectories starting in different state space regions. For example, the MCSOS (i.e. safe domain) is formed by the initial conditions of "safe" trajectories, whereas red indicates the initial conditions of trajectories crossing all respective planetary boundaries at some point in the simulation. Lines indicate the associated planetary boundaries of atmosphere, land and ocean in grey, green and blue, respectively.

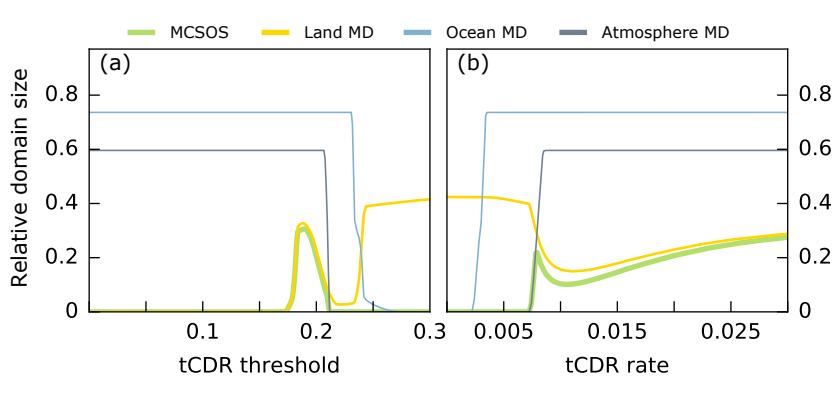

Figure 7. Relative size of domains in modelled carbon-system initial-condition state space for normalised parameter variation of (a) tCDR threshold (with $\alpha_{\max }=0.02$ ) and (b) tCDR rate (with $\left.\widetilde{C_{\mathrm{a}}}=0.2\right)$ for a medium emission scenario $\left(c_{\max }=0.4 \sim\right.$ $1600 \mathrm{Gt} C$ cumulative emissions). All domain sizes are given as shares of the state space region defined by a variation of the preindustrial conditions by \pm 0.2 .

Similar to the tCDR threshold, the parameter governing the maximal achievable rate of tCDR plays a decisive role for the existence of the MCSOS. With a tCDR implementation threshold not far below the atmospheric carbon boundary $\left(\widetilde{C_{\mathrm{a}}}=0.2\right)$, high $\mathrm{tCDR}$ rates are required in order to maintain a MCSOS. The tCDR starts being effective in maintaining a MCSOS at a rate of $\alpha_{\max }>0.007$ (corresponding to approximately $16.5 \mathrm{GtC} \mathrm{a}^{-1}$ with a fixed land carbon pool of 0.6 ). Rates smaller than that are not sufficient because of a lacking atmospheric MD (grey line in Fig. 7b).

As the tCDR threshold, the tCDR rate has a strong influence on the size of the land MD. For small tCDR rates, the land MD is sustained because of high atmospheric carbon concentrations and small biomass extraction. Rates higher than $\alpha_{\max }=0.0075$ result in a smaller land MD due to the over-exploitation of the photosynthetic productivity of the system which is reduced by both biomass removal and decreasing atmospheric carbon concentrations driving NEP. Higher rates, however, lead to overall smaller reductions of the land MD. This nonlinearity is evoked by the coevolutionary feedbacks between society and the carbon cycle, which lead to a deceasing tCDR flux if the system is in the atmosphere MD. Thus, sufficiently high tCDR rates lead to fast atmospheric carbon decrease and tCDR is switched off before the land system boundary is transgressed.

This analysis of the size of initial-condition state space domains suggests that the success of tCDR in sustaining the Earth system's persistence in the carbon SOS nonlinearly depends on the characteristics of tCDR implementation. On the one hand, foresightedness and anticipation of planetary boundaries are required to maintain the MCSOS, while on the other hand, too-early or too-intensive management could trigger co-transgressions of other planetary boundaries.

\subsection{Opportunities and limitations of tCDR}

While anticipation and appropriate management are necessary, the underlying emission scenario plays a major role in the resulting carbon dynamics. Figure 8 exemplarily depicts the relative MCSOS size for variations of tCDR characteristics (threshold and potential maximum rate) for emission pathways in accordance with RCP cumulative-emission scenarios. The window of opportunity for successful tCDR (i.e. the size of the MCSOS) decreases with increasing emission baselines and depends on the tCDR rate and threshold. In the case of the low-emission RCP2.6 scenario $\left(c_{\max }=0.2\right)$, the MCSOS can be sustained for a broad range of parameter values (Fig. 8a). The medium emission scenarios RCP4.5 $\left(c_{\max }=0.31\right.$; Thomson et al., 2011) and RCP6.0 $\left(c_{\max }=\right.$ 


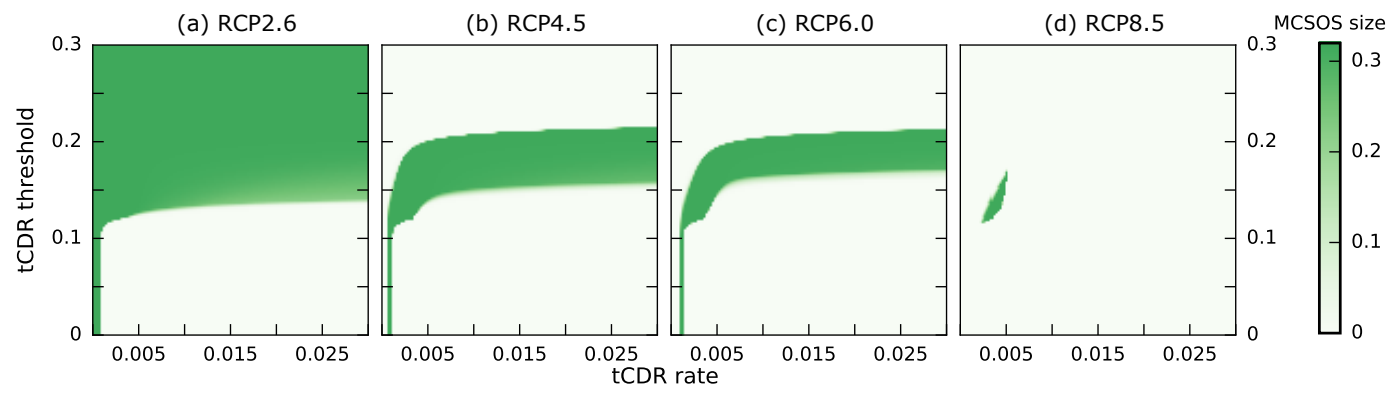

Figure 8. Relative size of the MCSOS for normalised parameter variation of potential maximum tCDR rate ( $x$ axis) and tCDR threshold ( $y$ axis) for different underlying emission scenarios: (a) RCP2.6 $\left(c_{\max }=0.2\right)$, (b) RCP4.5 $\left(c_{\max }=0.31\right),(\mathbf{c}) \mathrm{RCP} 6.0\left(c_{\max }=0.36\right)$ and (d) $\operatorname{RCP} 8.5\left(c_{\max }=0.51\right)$.

0.36; Masui et al., 2011) show a narrower range of tCDR characteristics that have the potential to sustain a MCSOS (Fig. $8 \mathrm{~b}$ and c). In a business-as-usual RCP8.5 scenario, the room for manoeuvring to maintain a MCSOS is very small (Fig. 8d).

Besides the dependence on the emission scenario, Fig. 8 highlights that for most emission scenarios the range of tCDR thresholds sustaining the MCSOS is narrow and depends on the tCDR rate. As discussed in Sect. 3.3 (for a fixed tCDR rate), tCDR thresholds higher than the atmospheric carbon boundary (0.21) are not sufficient in preventing a boundary transgression in the medium-to-high emission scenarios (Fig. 8b-d), whereas small tCDR thresholds lead to a transgression of the land system change boundary (unless tCDR rates are within a very narrow range smaller than 0.001). The variation of both the tCDR rate and threshold shows that smaller tCDR rates require a smaller minimal tCDR threshold as well as a smaller maximal threshold (Fig. 8b-d). This dependence of the success of tCDR on both the tCDR characteristics and the underlying emission scenarios highlights the relevance of societal intervention for global carbon dynamics. Essentially, tCDR intervention can trigger a nonlinear carbon system response through the land system when human carbon offtake exceeds NEP, which in turn causes a further reduction in NEP and tCDR potentials.

In our conceptual framework, tCDR can be effective in complementing climate change mitigation strategies as employed in low-emission scenarios. However, already an RCP4.5 emission scenario narrows the range of potentially successful management options significantly in comparison to RCP2.6 emissions. Under a business-as-usual pathway, tCDR cannot be applied to maintain a MCSOS in a resilient way. In contrast to prevailing reasoning of $\mathrm{CE}$ as an emergency action in case of dangerous climate change (Caldeira and Keith, 2010), tCDR would most likely not function as an emergency option under high-emission scenarios when additional sustainability dimensions reflected by other planetary boundaries are taken into account.

\section{Conclusions}

The introduced conceptual modelling approach - combining carbon cycle dynamics with a societal feedback loop of carbon monitoring and terrestrial carbon dioxide removal (tCDR) action - provides valuable insights into system-level constraints to navigating within the carbonrelated safe operating space defined by several interlinked planetary boundaries. Despite the fact that the reported results cannot be taken as exact quantitative prognostics of carbon pool evolution, our analysis has shown that employing tCDR for managing the atmospheric carbon pool does not necessarily safeguard the carbon cycle in the safe operating space because of nonlinear feedbacks between tCDR management and the carbon system.

The success of maintaining a manageable core of the safe operating space depends on the degree of anticipation of climate change, the potential maximum tCDR rate, as well as the underlying emission pathway. While tCDR might be successfully deployed as part of a strong climate change mitigation scenario, it is not likely to be effective in a businessas-usual scenario. Particularly, the focus on one planetary boundary alone (e.g. climate change), may lead to navigating the Earth system out of the carbon-related safe operating space due to collateral transgression of other boundaries (e.g. land system change). In light of numerous (economicallybased) integrated assessment studies proposing tCDR to counteract anthropogenic emissions, our conceptual results highlight that it is vital to include integrated sustainability assessments of more advanced models to the debate on climate engineering (CE) and climate change mitigation via tCDR. In the case of tCDR, the consequences for biosphere integrity, as well as trade-offs with agricultural land use and the biogeophysical climate system must be taken into account among other sustainability dimensions reflected by planetary boundaries and beyond.

In analogy to our analysis of tCDR, the approach followed in this paper could be transferred to other CE proposals such as ocean fertilisation or solar radiation management. Additionally, it would be of interest to extend the analysis pro- 
vided here and study Earth system dynamics under CE with more detailed models in line with the framework proposed by Heitzig et al. (2016), including a full topological analysis of the system with respect to the possibility of avoiding or leaving undesired domains, the reachability of desirable domains and the various management dilemmas induced by this accessibility structure.

\section{Data availability}

The model code and generated data are publicly available and can be accessed at https://github.com/pik-copan/ pycopanpbcc.

Author contributions. Vera Heck and Jonathan F. Donges designed the study. Vera Heck implemented and validated the model and also performed the simulations and analysis. Vera Heck prepared the manuscript, with contributions from all co-authors.

Acknowledgements. This research was performed in the context of Potsdam Institute for Climate Impact Research's flagship projects COPAN on Coevolutionary Pathways and OPEN on Planetary Opportunities and Planetary Boundaries. Vera Heck and Wolfgang Lucht were funded by the Deutsche Forschungsgemeinschaft in the context of the CE-Land project of the Priority Programme "Climate Engineering: Risks, Challenges, Opportunities?" (SPP 1689). Jonathan F. Donges thanks the Stordalen Foundation via the Planetary Boundaries Research Network (PB.net) and the Earth League's Earth-Doc Programme for financial support. The authors gratefully acknowledge the European Regional Development Fund, the German Federal Ministry of Education and Research and the Land Brandenburg for supporting this project by providing resources on the high-performance computer system at the Potsdam Institute for Climate Impact Research. The authors are grateful to Jobst Heitzig, Dieter Gerten, Tim Kittel, Wolfram Barfuss and the two referees for helpful comments and discussions.

Edited by: J. Dyke

Reviewed by: two anonymous referees

\section{References}

Anderies, J. M., Carpenter, S. R., Steffen, W., and Rockström, J.: The topology of non-linear global carbon dynamics: from tipping points to planetary boundaries, Environ. Res. Lett., 8, 044048, doi:10.1088/1748-9326/8/4/044048, 2013.

Batjes, N. H.: Total carbon and nitrogen in the soils of the world, Eur. J. Soil Sci., 47, 151-163, doi:10.1111/j.13652389.1996.tb01386.x, 1996.

Beringer, T., Lucht, W., and Schaphoff, S.: Bioenergy production potential of global biomass plantations under environmental and agricultural constraints, GCB Bioenergy, 3, 299-312, doi:10.1111/j.1757-1707.2010.01088.x, 2011.
Berkes, F., Folke, C., and Colding, J.: Linking Social and Ecological Systems: Management Practices and Social Mechanisms for Building Resilience, Cambridge University Press, 2000.

Brander, J. A. and Taylor, M. S.: The Simple Economics of Easter Island: A Ricardo-Malthus Model of Renewable Resource Use, Am. Econ. Rev., 88, 119-138, 1998.

Caldeira, K. and Keith, D. W.: The need for climate engineering research, Issues Sci. Technol., 27, 57-62, 2010.

Caldeira, K., Bala, G., and Cao, L.: The Science of Geoengineering, Ann. Rev. Earth Planet. Sci., 41, 231-256, doi:10.1146/annurevearth-042711-105548, 2013.

Ciais, P., Sabine, C., Bala, G., Bopp, L., Brovkin, V., Canadell, J., Chhabra, A., DeFries, R., Galloway, J., Heimann, M., Jones, C., Le Quéré, C., Myneni, R., Piao, S., and Thornton, P.: Carbon and Other Biogeochemical Cycles, in: Climate Change 2013: The Physical Science Basis. Contribution of Working Group I to the Fifth Assessment Report of the Intergovernmental Panel on Climate Change, edited by: Stocker, T., Qin, D., Plattner, G.K., Tignor, M., Allen, S., Boschung, J., Nauels, A., Xia, Y., Bex, V., and Midgley, P., 465-570, Cambridge University Press, Cambridge, UK and New York, NY, USA, 2013.

Crowley, T. J.: Ice Age terrestrial carbon changes revisited, Global Biogeochem. Cy., 9, 377-389, doi:10.1029/95GB01107, 1995.

Dornburg, V., Vuuren, D. V., Ven, G. V. D., Langeveld, H., Meeusen, M., Banse, M., Oorschot, M. V., Ros, J., Born, G. J. V. D., Aiking, H., Londo, M., Mozaffarian, H., Verweij, P., Lysen, E., and Faaij, A.: Bioenergy revisited: Key factors in global potentials of bioenergy, Energy Environ. Sci., 3, 258-267, doi:10.1039/B922422J, 2010.

Drake, B. G., Gonzàlez-Meler, A. M. A., and Long, S. P.: MORE EFFICIENT PLANTS: A Consequence of Rising Atmospheric $\mathrm{CO}_{2}$ ?, Annu. Rev. Plant Phys., 48, 609-639, doi:10.1146/annurev.arplant.48.1.609, 1997.

Foley, J. A., Costa, M. H., Delire, C., Ramankutty, N., and Snyder, P.: Green surprise? How terrestrial ecosystems could affect Earth's climate, Front. Ecol. Environ., 1, 38-44, doi:10.1890/1540-9295(2003)001[0038:GSHTEC]2.0.CO;2, 2003.

François, L. M., Delire, C., Warnant, P., and Munhoven, G.: Modelling the glacial-interglacial changes in the continental biosphere, Global Planet. Change, 16-17, 37-52, doi:10.1016/S0921-8181(98)00005-8, 1998.

Friend, A. D., Lucht, W., Rademacher, T. T., Keribin, R., Betts, R., Cadule, P., Ciais, P., Clark, D. B., Dankers, R., Falloon, P. D., Ito, A., Kahana, R., Kleidon, A., Lomas, M. R., Nishina, K., Ostberg, S., Pavlick, R., Peylin, P., Schaphoff, S., Vuichard, N., Warszawski, L., Wiltshire, A., and Woodward, F. I.: Carbon residence time dominates uncertainty in terrestrial vegetation responses to future climate and atmospheric $\mathrm{CO}_{2}$, P. Natl. Acad. Sci., 111, 3280-3285, doi:10.1073/pnas.1222477110, 2013.

Fuss, S., Canadell, J. G., Peters, G. P., Tavoni, M., Andrew, R. M., Ciais, P., Jackson, R. B., Jones, C. D., Kraxner, F., Nakicenovic, N., Le Quéré, C., Raupach, M. R., Sharifi, A., Smith, P., and Yamagata, Y.: Betting on negative emissions, Nature Clim. Change, 4, 850-853, doi:10.1038/nclimate2392, 2014.

Gao, Y., Skutsch, M., Masera, O., and Pacheco, P.: A global analysis of deforestation due to biofuel development, CIFOR, Center for International Forestry Research (CIFOR), CIFOR Working Paper no. 68, Bogor, 86 pp., Indonesia, 2011. 
Gillett, N. P., Arora, V. K., Matthews, D., and Allen, M. R.: Constraining the Ratio of Global Warming to Cumulative $\mathrm{CO}_{2}$ Emissions Using CMIP5 Simulations, J. Climate, 26, 6844-6858, doi:10.1175/JCLI-D-12-00476.1, 2013.

Gloor, M., Sarmiento, J. L., and Gruber, N.: What can be learned about carbon cycle climate feedbacks from the $\mathrm{CO}_{2}$ airborne fraction?, Atmos. Chem. Phys., 10, 7739-7751, doi:10.5194/acp10-7739-2010, 2010.

Guinotte, J. M. and Fabry, V. J.: Ocean Acidification and Its Potential Effects on Marine Ecosystems, Ann. NY Acad. Sci., 1134, 320-342, doi:10.1196/annals.1439.013, 2008.

Heck, V., Gerten, D., Lucht, W., and Boysen, L. R.: Is extensive terrestrial carbon dioxide removal a 'green' form of geoengineering? A global modelling study, Global Planet. Change, 137, 123 130, doi:10.1016/j.gloplacha.2015.12.008, 2016.

Heimann, M. and Reichstein, M.: Terrestrial ecosystem carbon dynamics and climate feedbacks, Nature, 451, 289-292, doi:10.1038/nature06591, 2008.

Heitzig, J., Kittel, T., Donges, J. F., and Molkenthin, N.: Topology of sustainable management of dynamical systems with desirable states: from defining planetary boundaries to safe operating spaces in the Earth system, Earth Syst. Dynam., 7, 21-50, doi:10.5194/esd-7-21-2016, 2016.

Hellmann, F., Schultz, P., Grabow, C., Heitzig, J., and Kurths, J.: Survivability of Deterministic Dynamical Systems, Scientific Reports, 6, 29654, doi:10.1038/srep29654, 2016.

Holling, C. S.: Resilience and Stability of Ecological Systems, Annu. Rev. Ecol. Syst., 4, 1-23, doi:10.1146/annurev.es.04.110173.000245, 1973.

Jarvis, A. J., Leedal, D. T., and Hewitt, C. N.: Climate-society feedbacks and the avoidance of dangerous climate change, Nature Clim. Change, 2, 668-671, doi:10.1038/nclimate1586, 2012.

Jones, P. D., Lister, D. H., Osborn, T. J., Harpham, C., Salmon, M., and Morice, C. P.: Hemispheric and large-scale landsurface air temperature variations: An extensive revision and an update to 2010, J. Geophys. Res.-Atmos., 117, D05127, doi:10.1029/2011JD017139, 2012.

Joos, F., Prentice, I. C., Sitch, S., Meyer, R., Hooss, G., Plattner, G.K., Gerber, S., and Hasselmann, K.: Global warming feedbacks on terrestrial carbon uptake under the Intergovernmental Panel on Climate Change (IPCC) Emission Scenarios, Global Biogeochem. Cy., 15, 891-907, doi:10.1029/2000GB001375, 2001.

Joos, F., Gerber, S., Prentice, I. C., Otto-Bliesner, B. L., and Valdes, P. J.: Transient simulations of Holocene atmospheric carbon dioxide and terrestrial carbon since the Last Glacial Maximum, Global Biogeochem. Cy., 18, GB2002, doi:10.1029/2003gb002156, 2004.

Joos, F., Roth, R., Fuglestvedt, J. S., Peters, G. P., Enting, I. G., von Bloh, W., Brovkin, V., Burke, E. J., Eby, M., Edwards, N. R., Friedrich, T., Frölicher, T. L., Halloran, P. R., Holden, P. B., Jones, C., Kleinen, T., Mackenzie, F. T., Matsumoto, K., Meinshausen, M., Plattner, G.-K., Reisinger, A., Segschneider, J., Shaffer, G., Steinacher, M., Strassmann, K., Tanaka, K., Timmermann, A., and Weaver, A. J.: Carbon dioxide and climate impulse response functions for the computation of greenhouse gas metrics: a multi-model analysis, Atmos. Chem. Phys., 13, 2793 2825, doi:10.5194/acp-13-2793-2013, 2013.

Kaplan, J. O., Prentice, I. C., Knorr, W., and Valdes, P. J.: Modeling the dynamics of terrestrial carbon storage since the
Last Glacial Maximum, Geophys. Res. Lett., 29, 31-1-31-4, doi:10.1029/2002GL015230, 2002.

Keenan, T. F., Hollinger, D. Y., Bohrer, G., Dragoni, D., Munger, J. W., Schmid, H. P., and Richardson, A. D.: Increase in forest water-use efficiency as atmospheric carbon dioxide concentrations rise, Nature, 499, 324-327, doi:10.1038/nature12291, 2013.

Kellie-Smith, O. and Cox, P. M.: Emergent dynamics of the climateeconomy system in the Anthropocene, Phil. Trans. A, 369, 86886, doi:10.1098/rsta.2010.0305, 2011.

Kirtman, B., Power, S., Adedoyin, J., Boer, G., Bojariu, R., Camilloni, I., Doblas-Reyes, F., Fiore, A., Kimoto, M., Meehl, G., Prather, M., Sarr, A., Schär, C., Sutton, R., van Oldenborgh, G., Vecchi, G., and Wang, H.: Near-term Climate Change: Projections and Predictability, in: Climate Change 2013: The Physical Science Basis. Contribution of Working Group I to the Fifth Assessment Report of the Intergovernmental Panel on Climate Change, edited by: Stocker, T., Qin, D., Plattner, G.-K., Tignor, M., Allen, S., Boschung, J., Nauels, A., Xia, Y., Bex, V., and Midgley, P., 953-1028, Cambridge University Press, Cambridge, UK and New York, NY, USA, 2013.

Knorr, W.: Is the airborne fraction of anthropogenic $\mathrm{CO}_{2}$ emissions increasing?, Geophys. Res. Lett., 36, L21710, doi:10.1029/2009GL040613, 2009.

Kriegler, E., Hall, J. W., Held, H., Dawson, R., and Schellnhuber, H. J.: Imprecise probability assessment of tipping points in the climate system, P. Natl. Acad. Sci., 106, 5041-5046, doi:10.1073/pnas.0809117106, 2009.

Lenton, T. M., Held, H., Kriegler, E., Hall, J. W., Lucht, W., Rahmstorf, S., and Schellnhuber, H. J.: Tipping elements in the Earth's climate system, P. Natl. Acad. Sci., 105, 1786-1793, doi:10.1073/pnas.0705414105, 2008.

Lucht, W., Schaphoff, S., Erbrecht, T., Heyder, U., and Cramer, W.: Terrestrial vegetation redistribution and carbon balance under climate change, Carbon Balance and Management, 1, 1-6, doi:10.1186/1750-0680-1-6, 2006.

MacMartin, D. G., Kravitz, B., Keith, D. W., and Jarvis, A.: Dynamics of the coupled human-climate system resulting from closedloop control of solar geoengineering, Clim. Dynam., 43, 243258, doi:10.1007/s00382-013-1822-9, 2013.

Masui, T., Matsumoto, K., Hijioka, Y., Kinoshita, T., Nozawa, T., Ishiwatari, S., Kato, E., Shukla, P. R., Yamagata, Y., and Kainuma, M.: An emission pathway for stabilization at $6 \mathrm{Wm}^{-2}$ radiative forcing, Clim. Change, 109, 59-76, doi:10.1007/s10584-011-0150-5, 2011.

Menck, P. J., Heitzig, J., Marwan, N., and Kurths, J.: How basin stability complements the linear-stability paradigm, Nat. Phys. 9, 89-92, doi:10.1038/nphys2516, 2013.

Motesharrei, S., Rivas, J., and Kalnay, E.: Human and nature dynamics (HANDY): Modeling inequality and use of resources in the collapse or sustainability of societies, Ecol. Econ., 101, 90102, doi:10.1016/j.ecolecon.2014.02.014, 2014.

NOAA National Centers for Environmental Information, State of the Climate: Global Analysis for Annual 2014, published online January 2015, available at: http://www.ncdc.noaa.gov/sotc/ global/201413 (last access: 25 November 2015), 2015.

Riahi, K., Rao, S., Krey, V., Cho, C., Chirkov, V., Fischer, G., Kindermann, G., Nakicenovic, N., and Rafaj, P.: RCP 8.5-A scenario 
of comparatively high greenhouse gas emissions, Clim. Change, 109, 33-57, doi:10.1007/s10584-011-0149-y, 2011.

Rockström, J., Steffen, W., Noone, K., Persson, Å., Chapin, F. S., Lambin, E. F., Lenton, T. M., Scheffer, M., Folke, C., Schellnhuber, H. J., Nykvist, B., de Wit, C. A., Hughes, T., van der Leeuw, S., Rodhe, H., Sörlin, S., Snyder, P. K., Costanza, R., Svedin, U., Falkenmark, M., Karlberg, L., Corell, R. W., Fabry, V. J., Hansen, J., Walker, B., Liverman, D., Richardson, K., Crutzen, P., and Foley, J. A.: A safe operating space for humanity, Nature, 461, 472-475, doi:10.1038/461472a, 2009.

Scheffer, M., Carpenter, S., Foley, J. A., Folke, C., and Walker, B.: Catastrophic shifts in ecosystems, Nature, 413, 591-596, doi:10.1038/35098000, 2001.

Schellnhuber, H. J.: Tipping elements in the Earth System, P. Natl. Acad. Sci., 106, 20561-20563, doi:10.1073/pnas.0911106106, 2009.

Shepherd, J., Caldeira, K., Cox, P., Haigh, J., Keith, D., Launder, B., Mace, G., McKerron, G., Pyle, J., Rayner, S., Redgewell, C., and Watson, A.: Working Group on Geoengineering the Climate, Geoengineering the climate: science, governance and uncertainty, London, UK, Royal Society, 98 pp., (RS Policy document, 10/29), 2009.

Smeets, E. M. W., Faaij, A. P. C., Lewandowski, I. M., and Turkenburg, W. C.: A bottom-up assessment and review of global bioenergy potentials to 2050, Prog. Energ. Combust., 33, 56-106, doi:10.1016/j.pecs.2006.08.001, 2007.

Snyder, P. K., Delire, C., and Foley, J. A.: Evaluating the influence of different vegetation biomes on the global climate, Clim. Dynam., 23, 279-302, doi:10.1007/s00382-004-0430-0, 2004.

Steffen, W., Richardson, K., Rockström, J., Cornell, S. E., Fetzer, I., Bennett, E. M., Biggs, R., Carpenter, S. R., Vries, W. D., Wit, C. A. D., Folke, C., Gerten, D., Heinke, J., Mace, G. M., Persson, L. M., Ramanathan, V., Reyers, B., and Sörlin, S.: Planetary boundaries: Guiding human development on a changing planet, Science, 347, 1259855, doi:10.1126/science.1259855, 2015.

Sutton, R. T., Dong, B., and Gregory, J. M.: Land/sea warming ratio in response to climate change: IPCC AR4 model results and comparison with observations, Geophys. Res. Lett., 34, L02701, doi:10.1029/2006GL028164, 2007.

Tans, P. and Keeling, R.: Mauna Loa $\mathrm{CO}_{2}$ annual mean data, ftp: //aftp.cmdl.noaa.gov/products/trends/co2/co2_annmean_mlo.txt (last access: 2 February 2016), 2015.
Thomson, A. M., Calvin, K. V., Smith, S. J., Kyle, G. P., Volke, A., Patel, P., Delgado-Arias, S., Bond-Lamberty, B., Wise, M. A., Clarke, L. E., and Edmonds, J. A.: RCP4.5: a pathway for stabilization of radiative forcing by 2100, Clim. Change, 109, 77-94, doi:10.1007/s10584-011-0151-4, 2011.

UNFCCC: Adoption of the Paris Agreement, FCCC/CP/2015/L.9/Rev1, (United Nations Framework Convention on Climate Change), http://unfccc.int/resource/docs/2015/ cop21/eng/10a01.pdf (last access: 3 September 2016), 2015.

van Kan, A., Jegminat, J., Donges, J. F., and Kurths, J.: Constrained basin stability for studying transient phenomena in dynamical systems, Phys. Rev. E, 93, 042205, doi:10.1103/PhysRevE.93.042205, 2016.

van Vuuren, D. P., Stehfest, E., Elzen, M. G. J. D., Kram, T., Vliet, J. V., Deetman, S., Isaac, M., Goldewijk, K. K., Hof, A., Beltran, A. M., Oostenrijk, R., and Ruijven, B. V.: RCP2.6: exploring the possibility to keep global mean temperature increase below $2{ }^{\circ} \mathrm{C}$, Clim. Change, 109, 95-116, doi:10.1007/s10584-0110152-3, 2011.

van Vuuren, D. P., Bayer, L. B., Chuwah, C., Ganzeveld, L., Hazeleger, W., Hurk, B. V. D., Noije, T. V., O’Neill, B., and Strengers, B. J.: A comprehensive view on climate change: coupling of earth system and integrated assessment models, Environ. Res. Lett., 7, 024012, doi:10.1088/1748-9326/7/2/024012, 2012.

van Vuuren, D. P., Lucas, P. L., Häyhä, T., Cornell, S. E., and Stafford-Smith, M.: Horses for courses: analytical tools to explore planetary boundaries, Earth Syst. Dynam., 7, 267-279, doi:10.5194/esd-7-267-2016, 2016.

Vaughan, N. E. and Lenton, T. M.: A review of climate geoengineering proposals, Clim. Change, 109, 745-790, doi:10.1007/s10584-011-0027-7, 2011.

Yuan, W., Luo, Y., Li, X., Liu, S., Yu, G., Zhou, T., Bahn, M., Black, A., Desai, A. R., Cescatti, A., Marcolla, B., Jacobs, C., Chen, J., Aurela, M., Bernhofer, C., Gielen, B., Bohrer, G., Cook, D. R., Dragoni, D., Dunn, A. L., Gianelle, D., Grünwald, T., Ibrom, A., Leclerc, M. Y., Lindroth, A., Liu, H., Marchesini, L. B., Montagnani, L., Pita, G., Rodeghiero, M., Rodrigues, A., Starr, G., and Stoy, P. C.: Redefinition and global estimation of basal ecosystem respiration rate, Global Biogeochem. Cy., 25, GB4002, doi:10.1029/2011GB004150, 2011. 